\title{
Open Educational Resources in Economics
}

Martin Poulter, the Economics Network m.1.poulter@bris.ac.uk Published September 2017

\section{Editors: \\ Prof. W. David McCausland, University of Aberdeen \\ Suzanne Hardy, \\ Newcastle University}

\section{Contents}

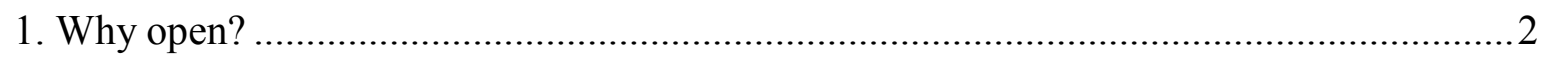

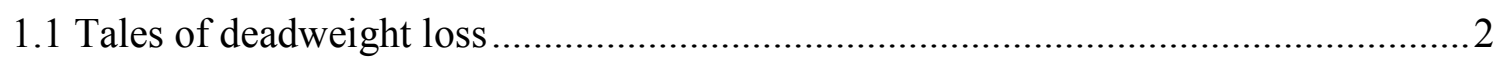

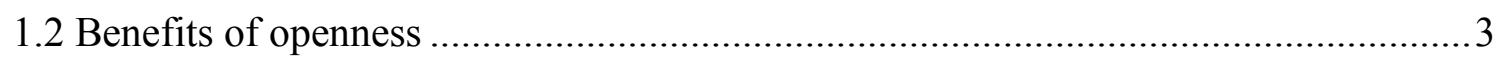

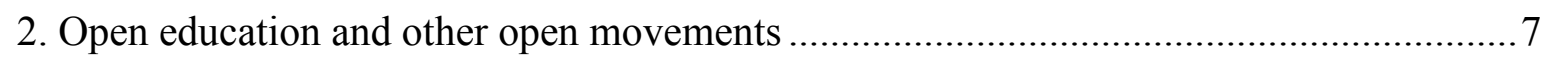

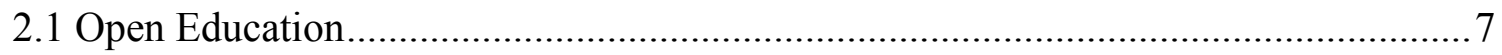

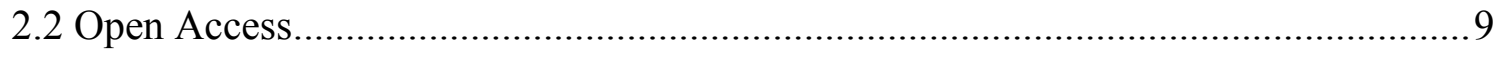

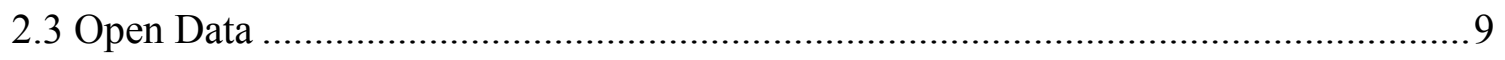

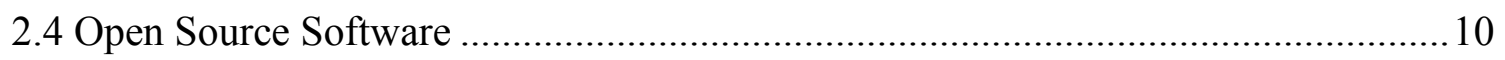

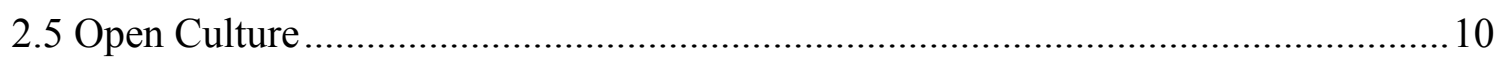

2.6 Top tips: correcting common misconceptions about the commons........................... 11

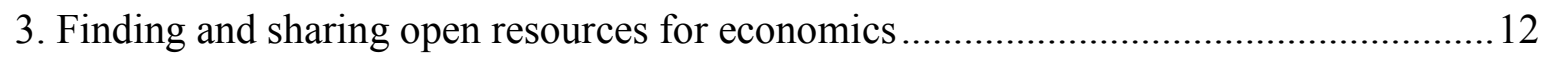

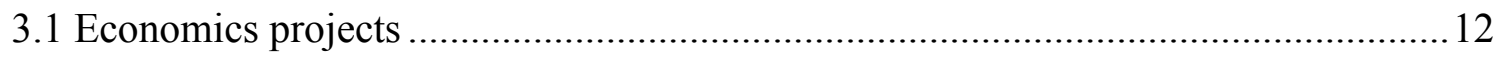

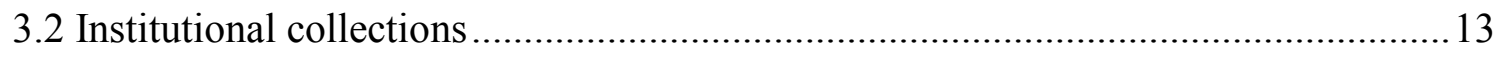

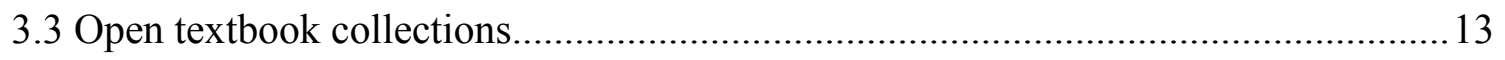

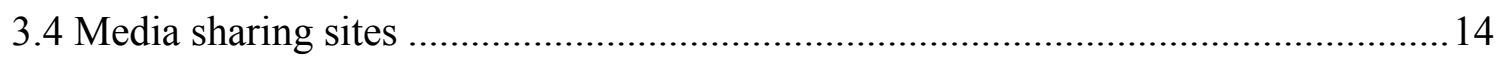

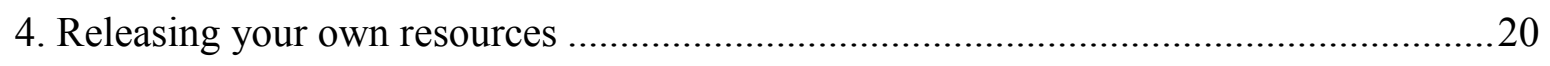

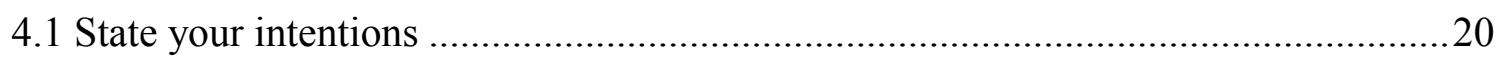

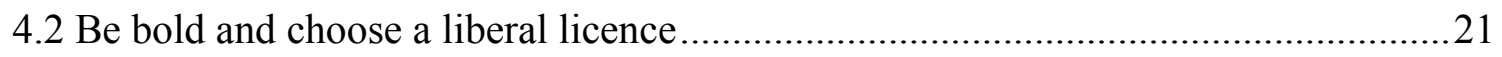

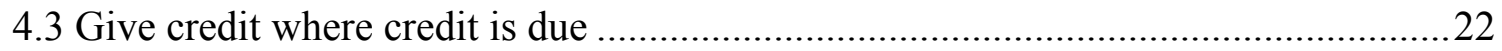

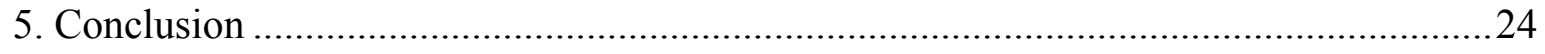

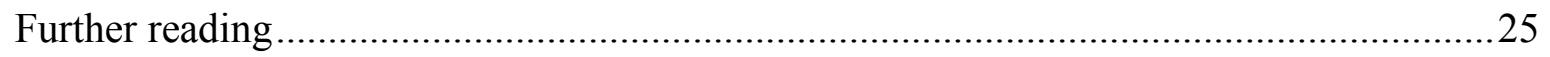

(i) (2) This work is licensed under a Creative Commons Attribution-ShareAlike 4.0 International License. 


\section{Why open?}

"[O]penness can be argued to be at the very core of higher education in the 21 st century. In its most positive interpretation it is the means by which higher education becomes more relevant to society, by opening up its knowledge and access to its services. It provides the means by which higher education adapts to the changed context of the digital world." -Martin Weller, "The Battle for Open"

-1.1 Tales of deadweight loss

-1.2 Benefits of openness

- 1.2 .1 Showcasing

- 1.2.2 Productivity

- 1.2 .3 Transformation

\subsection{Tales of deadweight loss}

This chapter is about sharing educational resources and about the wealth of educational material for economics that is freely available. Before we look at the advantages of sharing, consider the wasted effort in the current system. Situations like these may be familiar:

- An economist in another institution has created a witty introduction to their field with recommended readings, but now they've retired and are not on email, and the references are starting to look dated. You could copy the list and apply some updates, but you do not own the copyright. Copyright applies automatically to an original work whether the author makes a copyright statement or not, and, for written works, does not expire until seventy years after the author's death.[1]

- A decade ago, a couple of academics created a site that gives an engaging and original overview of their field. However, the site uses an animated navigation widget that does not work with modern browsers, and the site's authors have moved on to other careers. Just copying their content to another site and linking its pages together without the widget would help that content reach a new audience. The authors might be okay with this, but haven't declared the conditions for reuse of the site. They have moved on to other careers and their contact details no longer work.

-A funded project created a site with a set of educational materials. Now that the funding stream has ended and the staff have moved to other roles, it is no one's job to keep the site running. When the domain name elapses, the site will disappear although the material, with some tweaks, could still be useful.

We could do things differently. We could see copyright restrictions and technical barriers, that make sense in the commercial realm, as restricting educational resources from their full potential. When we create work, we could declare our intentions for it up front, so people do not have to take time asking us. We could work to free up education from some of these barriers while maintaining quality and making sure that creators of materials are properly credited. 
This "opening up" of content can be done at any scale. The term "Open Educational Resources" can encompass institutional projects to put all course materials online by default, or it can refer to someone sharing a photograph on a site such as Flickr, with permission for other people to use it in teaching (Weller (2010)).[2]

\subsection{Benefits of openness}

The benefits to learners, teaching staff, and universities of releasing open educational resources have been widely studied.[3] For the purposes of this chapter, they can be grouped under three main headings:

- Showcasing: open course materials are encountered outside academia, contributing to a better-informed public, especially to better-informed prospective students.

- Productivity improvements: things that we do anyway can be done more easily, to a higher standard and more sustainably.

- Transformation: a changed environment of educational resources enables (some would say requires) new approaches to teaching.

\subsubsection{Showcasing}

The free availability of education resources means prospective students are potentially better-informed about university subjects and about individual courses. Insofar as they take this opportunity, this should result in better enrolment choices and, down the line, greater satisfaction. The Open University has made a particular success of marketing courses by releasing open resources, generating thousands of new student enrolments (Weller (2010)).

The platforms considered later in this chapter, such as YouTube and iTunesU, are marketplaces of ideas in which market share produces tangible gains. Some institutions are highly visible on these platforms, but many are not. Those who make themselves visible by sharing good materials in a subject, as the Open University have done for many subjects including economics, create an association between that subject and their institution, especially among people who have not yet thought about formally studying the subject. Institutions that choose not to engage are, in effect, choosing to be less wellknown.

A corollary of this benefit is better management of intellectual property. A formal process for releasing material openly online, including free licences, makes clear the rights of the university, the staff member, and third parties. If the staff member moves to another institution, they can continue to use the materials they've created even if the institution owns their copyright. Depositing materials in a public online archive makes it easy to show primacy if those materials are copied by someone else.

\section{Top Tip:}

If you are collaborating to create educational or reference materials, take a group decision right at the start about intellectual property. Will this be an open resource that people can adapt, or will you keep all copyright protections, with risks for sustainability? Licences are discussed in Section 4. 


\subsubsection{Productivity}

Each course is different, and each lecturer is different. Any course will mix core concepts with the lecturers' own ideas and examples. Open sharing is an opportunity to reduce duplicated effort in producing diagrams and graphs that are used in many courses. It is also an opportunity to specialise and trade, spending more time on what is distinctive to your own course and your own style of teaching.

As educational materials become more of a shared, global resource, individual teaching staff have more opportunity to reach a global audience, whether by sharing their lectures on YouTube, or creating text or interactive tutorials. A star lecturer would previously have audiences in the hundreds. Now, they can have audiences of hundreds of thousands, via lecture capture and video sharing sites such as YouTube.

From the students' perspective, shared resources give them a much broader set of explanations to draw on for any given topic, so they have more ways forward if the textbook's or lecturer's explanation does not work for them.

In this context, shared learning resources does not mean greater intellectual uniformity. The open approach is about sharing and remixing, removing duplicated effort in production of "core" materials, so it actually favours intellectual diversity. For instance a standard set of materials explaining the axioms of rational choice theory could be annotated with explanations of why the axioms are implausible as descriptions of individual human choices. A detailed diagram of an economic model could be used in different educational contexts and educational levels, depending on how it is presented and annotated.

The quality of resources is naturally going to be more important to learners and educators than their licence, but ease of access is also important to them, especially for learners whose study involve multiple spaces and devices; a laptop at home, a mobile device on the bus, and other devices in a department or library.

The Finance and Economics Experimental Laboratory at Exeter (FEELE) lab used Wikiversity (one of Wikipedia's sister sites) to document a range of Economics Classroom Experiments in 2007 and 2008. The Wikiversity community have recognised the quality of the material, badging the collection as a Featured Resource. They have taken care of keeping the software up to date, fixing vandalism and correcting minor errors. The open platform means that this material can be shared more sustainably than if it were on its own dedicated server.

Some of the open resources considered later in this chapter are remixable textbooks. Roshan Khattry, who introduced an open textbook at Spokane College in the US, found that adapting it to the course took a lot of work, but gave more autonomy to the course leader. Whereas a failing of a traditional textbook would have to be raised and discussed in a committee, adapting the open textbook is something he can do straight away.[4]

\subsubsection{Transformation}

The OER Research Hub is a long-term project to evaluate claims about OERs. In a report they published in 2014, they find strong evidence that "OER use and exposure 
leads to reflection on practice by educators. It causes them to incorporate a wider range of content, to consider different teaching approaches and to reflect upon their role as educator."[5] One driver of transformation is the change in teaching practice as staff are exposed to a greater variety of ways of explaining economic concepts. Another driver is the changed expectations of students, who have seen some of this variety online.

One aspect of changed pedagogy is the flipped classroom, where students watch video tutorials, and what was lecture time is used for other activities such as problem solving, case studies, or debates. Shirky (2005) observes, "We ask students to read the best works we can find, whoever produced them and where, but we only ask them to listen to the best lecture a local employee can produce that morning."[6] Flipping is discussed in the Lectures chapter of this handbook.

Online access to the best lecturers or best animations will mean that students are better informed about economics and about specific concepts, but will also raise student expectations about their experience of university. It will mean lecturers spend less time repeating the standard presentation of the standard concepts, and more time finding their own memorable mark on the topic, whether in examples or delivery.

The advent of drum machines and similar music technology prompted a wave of interest in James Brown records whose drummers did a lot more than just keep the beat. While the technology undercut the demand for mediocre drummers, it created a premium for that hard-to-capture soulful quality. As online resources and communities make explanations of economic topics more freely available, institutions and instructors need to discover and emphasise their own distinctive offering.

Another way openness drives transformation is that students need to be more involved in the selection and evaluation of resources. No matter what is on the reading list provided by the lecturer, the ease and immediacy of Google and similar tools mean that students will turn them for help understanding difficult concepts. In effect there is a "shadow reading list" of material that students are finding online, which will be of varying quality. So critically evaluating resources for their credibility and relevance to the course needs to be no longer the preserve of the course leader but done collaboratively between learners and staff. The skill of critical evaluation needs to be introduced early on in the course and develop in parallel with understanding of the subject.

These examples illustrate that by responding to the way open resources have transformed the online world, courses become more student-centred: this is how open educational resources lead eventually to open educational practice.[7]

It is not obvious on first inspection, but some of Wikipedia's articles on economic topics were written by university students in exchange for credit. A Rice University module on Poverty, Justice and Human Capabilities has substantially improved many articles over the years, among them Water scarcity, Illegal drug trade, Food security, Microfinance, and Economy of Nicaragua. As well as improving their chosen articles, following the site's guidelines, students had to review each other's work and respond to feedback and review from the Wikipedia community.

Although there is a stage fright to overcome about writing in the open, the student authors are rewarded with a very wide readership: the five articles mentioned get well 
over a million hits per year between them. This sort of activity illustrates that open education is are not just about free supplements or alternatives to standard textbooks, but more active and creative ways for students to engage with resources.

\section{Footnotes}

1. "How copyright protects your work" Gov.uk https://www.gov.uk/copyright

2. Weller, Martin (2010). Big and little OER. In: OpenED2010: Seventh Annual Open Education Conference.

http://oro.open.ac.uk/id/eprint/24702

3. The benefits listed in this section draw on:

David Mossley (2013) Open Educational Resources and Open Education. Higher Education Academy

https://www.heacademy.ac.uk/content/open-educational-resources-and-open-education

HE Academy/ Jisc (2012) “Open Educational Resources: An introduction for managers and policymakers"

https://www.webarchive.org.uk/wayback/archive/20140614151559/http://www.jisc.ac.u $\mathrm{k} /$ media/documents/programmes/OER3/OER-\%20Web\%20ready.pdf

Open Michigan (2011) “Open Educational Resources: Benefits for Faculty and Students"

http://web.archive.org/web/20160622052549/http://open.umich.edu/sites/default/files/36 59/PDFs/OER-benefits-handout.pdf

4. Scott Jaschik (26 April 2017) "OER, on the ground" Inside Higher

$E d$ https://www.insidehighered.com/digital-learning/article/2017/04/26/faculty-memberand-librarians-discuss-how-college-makes-progress

5. de los Arcos, B., Farrow, R., Perryman, L.-A., Pitt, R. \& Weller, M. (2014). OER

Evidence Report 2013-2014. OER Research Hub.

https://oerresearchhub.files.wordpress.com/2014/11/oerrh-evidence-report-2014.pdf

6. Clay Shirky (17 December 2012) "Higher education: our MP3 is the mooc" The

Guardian

https://www.theguardian.com/education/2012/dec/17/moocs-higher-education-

transformation

7. OpenMed project (2017) "OEP in your daily teaching"

https://coursecomments.openmedproject.eu/wp/m5-open-educational-practices/5-2-oepin-your-daily-teaching/ 


\section{Open education and other open movements}

There are movements towards openness in education, in research, in public services, in heritage organisations such as museums, and in creative fields such as photography and music. These different movements support each other: an educator creating slides can draw on freely available photographs from archives, or figures from open-access research papers. Hence it is worth taking a quick overview of five kinds of "open" and the links between them.

All the open definitions centre on the rights of users: the right to access and use something, adapt it, and republish the thing or its adapted versions while appropriately crediting its original authors. Often these are phrased as freedoms, and sometimes the adjective "free" is used rather than "open" (as in "Free Software movement" or "Wikipedia, the free encyclopedia") but the ambiguity of the word "free" can be confusing. This chapter will use "open".

\section{Contents}

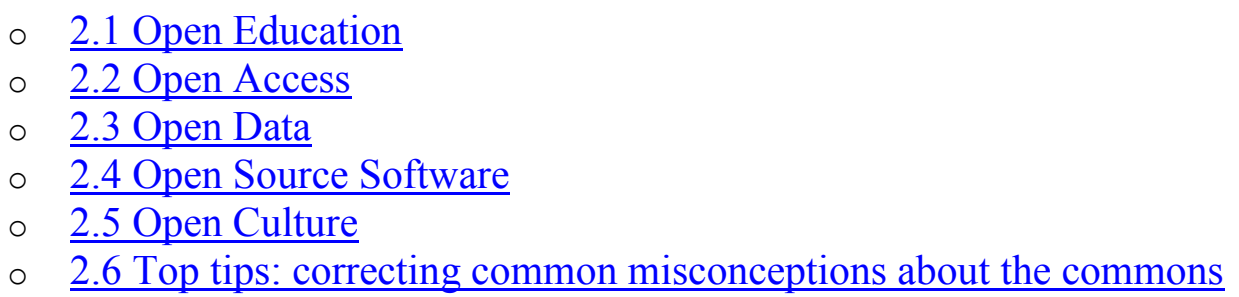

\subsection{Open Education}

The Cape Town Open Education Declaration (2007) asks all educators to release their resources openly, arguing that this "will help teachers excel in their work and provide new opportunities for visibility and global impact. They will accelerate innovation in teaching. They will give more control over learning to the learners themselves."

"Open Education" encompasses more than just whether resources for learning are openly and freely accessible. The Cape Town definition includes innovative approaches to assessment and collaborative learning. The term Open Educational Practices (OEPs) captures this idea that open education is not just about resources, but about the context and practice of learning.

The open education movement has evolved in multiple, even contradictory ways over the past decade. One outcome of this evolution is a large amount of educational material freely accessible online, often driven by charities and other funding bodies. We look at some of this in detail in the next chapter.

Another outcome is the growth of online courses open to public enrolment. The term Massive Open Online Course (MOOC) has become fashionable, although it is almost always a misnomer.[1]

Some courses using the MOOC label are massive in the sense of attempting to build a network of interactions between learners, encouraging them to respond to the course 
material, and each other, in varying forms across multiple online platforms. A different kind of MOOC has become more common: a kind of Virtual Learning Environment with public enrolment, connecting a large number of people to video lectures, quizzes or worksheets, and discussion forums. Often these are supported by a commercial start-up company in partnership with a university. So there are MOOCs that involve some abdication of status by the course leader in the service of a distinctively online, distributed context for learning,[2] while others bring a more didactic form of teaching to a mass audience, building on and reinforcing the star status of the best-known lecturers.

While they were initially promoted as a challenge to the fundamental business model of universities, enthusiasm (and fear) for MOOCs has waned and they are now more likely to be seen as a marketing option; not sustainable in themselves, but viable as a way to publicise conventional courses and institutions.[3] One way the MOOC label is misleading is that MOOCs do not usually lead to substantial sharing of resources on the open internet, although they offer learning experiences rather than mere access to resources.

Widely different positions on a spectrum of open education are illustrated by visiting MIT OpenCourseWare (an open archive of educational resources) and FutureLearn (a UK-based MOOC platform). OpenCourseWare makes complete sets of course material freely accessible. Its long-term nature means that a large amount of material is available, including a lot that is out of date. By contrast, FutureLearn is very time-specific and frequently changing. At the time of writing it offers several opportunities to sign up for economics-related courses running in the near future, but no chance to look over what staff or learners produced in previous courses.

The people best-placed to benefit from a mass online course are usually those with the subject background and intellectual discipline gained from already having a degree. So while MOOCs were initially promoted as democratising the world of education and promoting equality, their greatest benefits have gone to those who are already well provided-for.[4]

Alongside the changes within higher education there have been other developments bringing education to the masses, less remarked-upon because they are happening in plain sight. Mainstream online communities are increasingly being used for learning activities. YouTube videos about mathematical and scientific subjects get a large audience: it is not hard to find videos on economic topics that have half a million views. Communities where people share and remix images, such as Flickr and Wikimedia, have created tens of millions of images with a educational purpose. The barrier between formal learning "in academia" and informal learning has eroded as more university courses make use of these platforms.

Comment and discussion features on sites like YouTube can bring out the most illinformed opinions but, when the will is there, online communities can support a conversation that is respectful and substantive while still involving large numbers of people. The discussion site Reddit has Ask Me Anything (AMA) events where academic experts answer questions that have been voted on by the community. Economists taking this opportunity include macroeconomist Brad DeLong, Marxist Richard D Wolff and 
libertarian Bryan Caplan. Online discussions can also bring campus-based students into contact with external experts such as entrepreneurs.

Blogging is another way an academic expert can build up a set of resources through an ongoing dialogue; posting their own observations or commentary on other sources and generating responses from the public.

\subsection{Open Access}

The open access movement presses for papers and other outputs of research to be available to the public without restriction. In the language of the Budapest Open Access Declaration (2002), this level of access will "accelerate research, enrich education, share the learning of the rich with the poor and the poor with the rich, [and] make this literature as useful as it can be".

On the recommendation of the UK Government's 2012 Finch Report, Research Councils UK and the Higher Education Funding Council for England have taken up policies that encourage publicly-funded research to be published openly under licences that permit adaptation and reuse.[5]

One link between open access and open education is that if more research is freely available online, students and independent learners can consult it through home and mobile networks as easily as on-campus. This is one reason why student voices are prominent among those calling for open access, such as the Right to Research Coalition.

Another link is that if research publications can be adapted for other purposes, they can be adapted into educational materials. For example, the figures from an open access research paper could be used in educational slides or summaries.

\subsection{Open Data}

Data that are published are not necessarily open. A data table in a PDF document is not directly linkable and it is not guaranteed that applications will be able to extract it and process it. Even data that are easily accessible can still have legal restrictions. Open data is defined by having no technical or legal restrictions on its reuse. The Panton Principles summarise the Open Data movement's goal that "data related to published science should be explicitly placed in the public domain."

Open data are increasingly seen as essential infrastructure for business and research, including by the World Bank and by the G8 countries, who have committed to making a lot of their public-sector data openly available. In the UK, these are published on the Data.gov.uk portal.

One open data project that supports education is Wikidata, a sister project of Wikipedia. This human- and machine-readable database makes

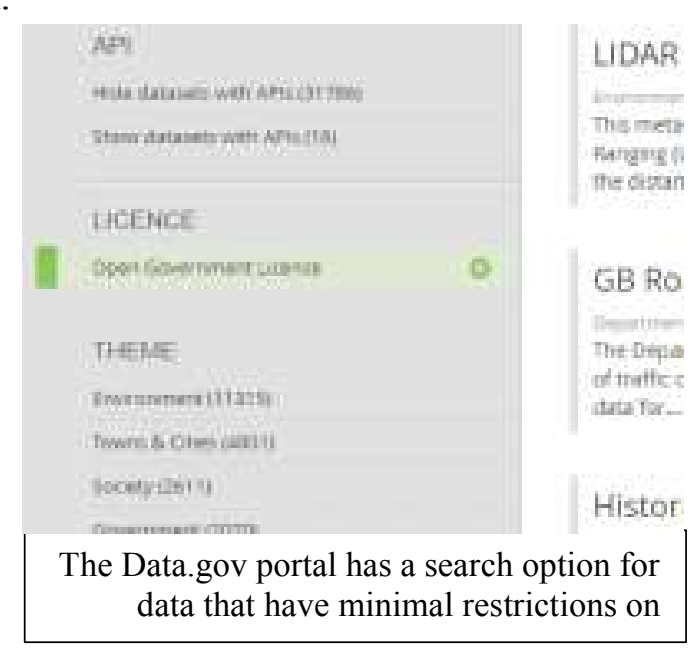


it possible for programmers to create interactive objects such as maps of economists' birthplaces.

\subsection{Open Source Software}

When software is open source, its underlying code is published, rather than the confidential property of the authors. Users can study what the code is doing, which is useful when the code uses private information (such as a web browser) or when it is crucial to research. The designation "free software" implies that users can also alter and redistribute the code. Open source software is ubiquitous: the Internet would not function without it, nor would Android phones or Apple devices. Services like Github enable public sharing of code along with version-tracking and collaboration.

Open source and open data connect to the reliability of research. It is one thing to read that an analysis of a data set gives a particular result; another to have access to the data and code needed to replicate the analysis. Students could even conduct a replication as an assignment and share their results, contributing to open education. That is the idea behind ReplicationWiki, a project hosted by the University of Göttingen to encourage replications of econometric research. ReplicationWiki includes a database of published studies that have not been replicated, and allows users to record successful or failed replications as well as difficulties getting hold of the raw data.

\subsection{Open Culture}

Any kind of creative work, including images, music, or video, can be freely reusable or have all rights reserved. By default, copying requires the permission of the copyright owner. Since Adam Smith's and Thomas Malthus' works are out of copyright, there are editions of Wealth of Nations or Essay on the Principle of Population that you can distribute freely without permission, even an altered version with annotations. Just grab the text from the History of Economic Thought archive or Wikisource.

Copyright applies automatically to an original creative work, and normally elapses seventy years after the creator's death (though there are several exceptions, such as a shorter term for and broadcasts and sound recordings).[6] If default copyright protections are too restrictive - for example if something is best used by being shared widely - the creators or owners can use an open licence to encourage reuse. In the UK, new government publications (for example from the Treasury) by default have the permissive Open Government Licence. No permission is needed to adapt them for educational use or other purposes, so long as you follow the terms of that licence, which include citing the source.

Open culture supports open education in that, if you are looking to create freely reusable educational materials, the source images or other content need to be freely reusable. Even if your own materials are not open, it's an advantage if you can use a variety of images and other source materials, knowing there is no requirement to pay royalties or obtain permission from the owner. Later on in this handbook chapter we will look at finding freely reusable images, video, and audio. 


\subsection{Top tips: correcting common misconceptions about the commons}

-Working in the open does not allow other people to misrepresent your work. The rights to copy and alter a creative work are just one set of intellectual property rights: moral rights, such as the right to object to derogatory treatment or to object to false attribution, are a separate area, and are not sacrificed by adopting an open licence. So when you allow your work to be copied, you are not giving others permission to pass off your work as their own, nor to claim their work as yours.

- Open is not the same as Creative Commons. Making research outputs or educational materials openly remixable often involves reserving some rights via a CC licence, instead of the default "all rights reserved", However, not all CC licences are appropriate, and $\mathrm{CC}$ licences themselves do not necessarily mean open education. There are several varieties of Creative Commons licence and some of them forbid any alteration to the material. Certain formats such as PDF are hard to alter: opening up that content involves not just a liberal licence, but sharing the Word document or LaTeX source. Open is better thought of as an attitude towards collaboration and reuse, facilitated by $\mathrm{CC}$ licences amongst other tools.

\section{Footnotes}

[1] David Wiley (1 July 2012) “The MOOC misnomer”

[2] K. Masters. "A Brief Guide To Understanding MOOCs". The Internet Journal of Medical Education. 2011 Volume 1 Number 2. DOI: 10.5580/1f21

[3] Steve Kolowich (5 February 2015) “The MOOC Hype Fades, in 3 Charts" The Chronicle of Higher Education

Ioana Literat (2015) "Implications of massive open online courses for higher education: mitigating or reifying educational inequities?", Higher Education Research \& Development, 34:6, 1164-1177, DOI: 10.1080/07294360.2015.1024624

[4] Ioana Literat (2015) op. cit.

[5] Higher Education Funding Council for England (July 2015) "What is Open Access?" In Policy Guide: Open Access Research

[6] The National Archives (2013) "Copyright and related rights" 


\section{Finding and sharing open resources for economics}

The tools for finding and sharing open resources include tailored collections of material, specialist educational databases, and general web search engines. Some tools are dedicated to open educational resources, while others combine open resources with other categories.

With any tool for finding material, there is a tradeoff. A general sharing site such as YouTube will host anyone and everyone's opinion on economic topics, from conspiracy theorists to Nobel laureates. An institutional showcase will have higher overall quality but is less likely to have exactly what you want. Lacking the time to post your material to every possible forum, you face that same trade-off when sharing materials: whether to put things on mass-audience sites where most people are looking for them, or on specialist sites where they will be highlighted.

One starting point is the Economics Network links database which is regularly updated with educational resources across dozens of economic topics. Resources with open licences appear higher up on the page. Merlot is a US-based database which links to more than a thousand educational resources for economics, with options for users to comment and review.

-3.1 Economics projects

-3.2 Institutional collections

- 3.3 Open textbook collections

-3.4 Media sharing sites

\subsection{Economics projects}

Among the many publicly-funded projects hosting open educational resources, some are specific to economics, or to the social sciences. Although the official funding period for these projects is over, it is still possible to add your own materials to these showcases.

\section{TRUE}

Teaching Resources for Undergraduate Economics is a series of sub-sites hosted by the Economics Network, sharing resources for second and third year economics modules under a Creative Commons NonCommercial Attribution licence. Each has been set up by an academic subject specialist, and it is still possible to submit material of any kind to showcase on the site.

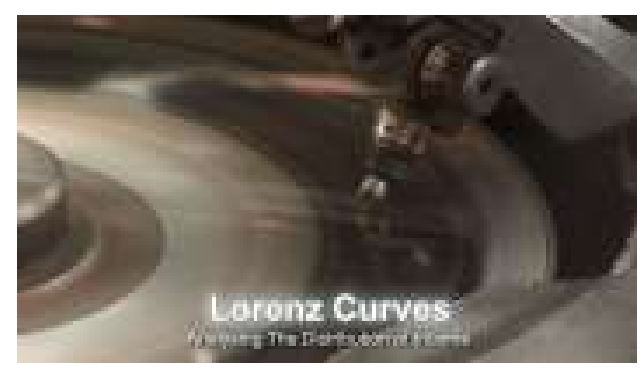




\section{DeSTRESS}

DeSTRESS is a collection of reusable resources for contextualising statistics in social sciences. It includes twenty professionally-produced videos hosted by Ken Heather of the University of Portsmouth, along with handouts, interactive graphs and other types of resource. The videos can be watched on YouTube or downloaded directly for offline use.

\section{METAL}

A forerunner of DeSTRESS, the METAL project consists of various resources to help teach mathematical concepts in a setting of real-world economics decisions. They include a set of 73 videos, shorter than the DeSTRESS videos, presented by Ken Heather, with worked examples. The materials have a variety of licences.

\subsection{Institutional collections}

Some institutions run their own repositories of freely reusable materials as a way to drive interest in their courses and to support open education. A few of them have substantial amounts of material relevant to economics.

MIT OpenCourseWare started in 2001 and has been very influential in the open education movement. Thousands of courses - including dozens in Economics - are represented in some form: sometimes just a reading list, sometimes a complete set of course materials.

The University of Nottingham's repository, U-Now, has a variety of materials including slides and audio podcasts. The Open University has OpenLearn, which is strong in introductory material for economics and statistics.

\subsection{Open textbook collections}

\section{OpenStax}

OpenStax is a charity, connected to Rice University, which is creating a set of peerreviewed open textbooks, including one in Economics. All their material has a very liberal licence so readers can do practically anything they like with the material as long as they attribute the source. You can browse community-created remixes which provide free alternatives to specific editions of commercial textbooks. OpenStax are partners in the UK Open Textbook Project which is adapting textbooks for the UK and building a network of adopters.

\section{CORE}

CORE is based at University College, London, and backed by a consortium of universities in the UK and internationally. Its funders include HM Treasury. It has created an e-book and related resources to support a distinctively post-crash module in economics, with topical illustrations of central ideas, examples driven by data, and broader theoretical perspectives than standard modules. The licence is Creative 
Commons Attribution-NonCommercial-NoDerivatives so it is possible to copy content to other platforms for educational use.

\section{Saylor}

Saylor Academy is another charity offering sets of course materials to cover core modules in Economics and other subjects. A lot of their content consists of links to materials elsewhere online, such as Khan Academy videos. Some of these modules are under active development; those that are not are in a dedicated "legacy" area of the site.
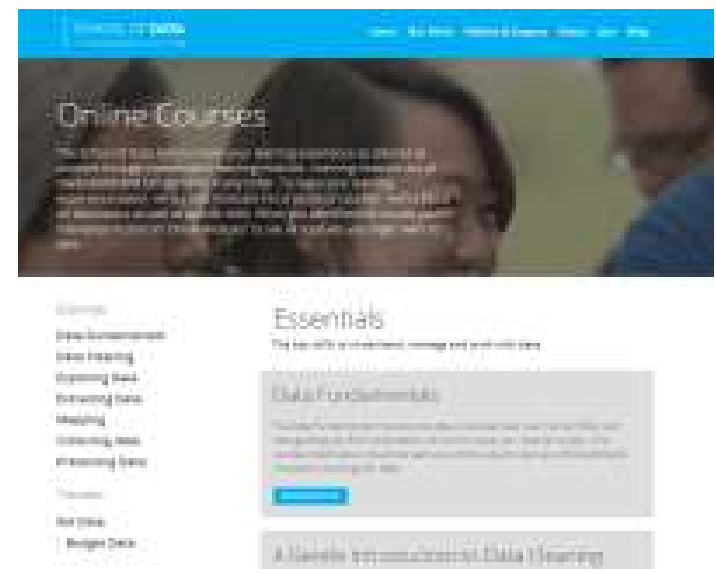

\section{School of data}

This is an unusual charitable project, providing not a conventional textbook but dozens of online modules aiming to help learners work with data, including "How is aid data used in the media?" They encourage copying and adaptation of their materials.

\section{Boundless}

Boundless is a company offering textbooks and related materials under a licence that allows copying and adaptation. There are intrusive adverts scattered through the content for unregistered users. For those who want to pay, the site offers a learning management system.

\section{Wikibooks}

This is a sister-site of Wikipedia, using the same collaborative process to create open textbooks. The economics section of Wikibooks is mostly a graveyard of skeletal books that were started off with good intentions but abandoned. On the other hand, the platform allows interesting projects, including those in which students create their own textbook. The Bestiary of Behavioral Economics, created by students in 2012, is an example.

\subsection{Media sharing sites}

Most people looking for an economics video will go to a video site and search for "economics" rather than the other way round. Image-sharing and video-sharing sites are among the first places that anyone looks. This section looks at some of the most popular 
sites, in each case describing what it does, a key strength and key weakness, and examples relevant to economics.

\section{YouTube}

Although there are competitor sites, YouTube is where most video gets uploaded and watched. It is open to anyone with an opinion, so although there is a large amount of academic material, it is surrounded by political rants and conspiracy theories. A lot of YouTube's educational content in economics is listed in the Economics Network's Video and Audio index, but even this is just the tip of the iceberg.

YouTube's strengths are that its videos can be embedded in other sites, and that viewers with an account can subscribe to channels they are interested in and be notified of new videos. You can organise videos - your own or other people's - into playlists which have their own link; for example the sequence of videos associated with a particular course.

Contributors benefit from extensive analytics, showing how many people viewed each video, how much time they spent watching and how they responded. The comments sections of YouTube are notoriously infantile, but video owners can set it so that comments have to be approved before being publicly visible. In 2010, the Open University reported that their most popular YouTube videos were getting more views than television broadcasts on $\mathrm{BBC} 4$ or even $\mathrm{BBC} 2$.[1]

When uploading a video, you can choose either the Standard YouTube Licence (which effectively reserves all rights, but lets YouTube host and distribute the video) or a Creative Commons Attribution-only (CC-BY) licence. YouTube has a built-in video editor that allows users to create videos from existing, suitably licensed YouTube videos, and which automatically credits and links the source videos. If your videos have another CC licence, you can specify it in the description. Almost all the video lectures shared by the University of Utah Economics Department have the attribution-only licence.

- Strength: Huge volume of material, easily bookmarked or integrated with other materials and clearly labelled with what is fully copyrighted and what is freely reusable.

-Weakness: Comments and "related" videos can drag viewers into conspiracy theories and other junk.

\section{Top tip:}

Once you do a search in YouTube, click "Filters" to bring up a menu of ways to customise the search. You can restrict the search to videos shorter than 4 minutes, videos uploaded in the past year, or freely remixable videos, among other options. 


\section{$\equiv$ YouTube}

Filters

$\begin{array}{lllll}\text { Upload date } & \text { Type } & \text { Duration } & \text { Features } & \text { Sort by } \\ \text { Last hour } & \text { Video } & \text { Short }(<4 \text { minutes }) & 4 \mathrm{~K} & \text { Relevance } \\ \text { Today } & \text { Channel } & \text { Long }(>20 \text { minutes }) & \text { HD } & \text { Upload date } \\ \text { This week } & \text { Playlist } & \text { Subtitles } / C C & \text { View count } \\ \text { This month } & \text { Movie } & \text { Creative Commons } & \text { Rating } \\ \text { This year } & \text { Show } & 3 \mathrm{D} & \\ & & \text { Live } & \\ & & \text { Purchased } & \\ & & 360^{\circ} & \end{array}$

\section{Wikimedia Commons}

This is a media repository hosted by the same charity behind Wikipedia, and maintained by a similar volunteer community. The name reflects that all the files here (mainly photographs and diagrams, but also some video and audio clips) are freely reusable by anyone for any purpose. Each file comes with different download options and, when you scroll down, the conditions for reuse, which vary.

Almost all of the images that illustrate Wikipedia and Wikiversity are hosted on Commons, and the site's purpose is to help resources created on these and other education or reference sites. For this reason, Commons is solely for images with educational or research value, although that is interpreted very broadly. This means the site avoids the huge numbers of holiday snaps and "selfies" that pour onto other imagesharing sites. A lot of the images here have come from museums, libraries and archives, or even from figures in open access research papers. The site is multilingual so, on searching for a particular diagram, you might find the exact type you want, but labelled in the wrong language.

If an image was generated by a piece of code, it is possible to include the code along with the image, including links to data sources. The Wikipedia article on TED Spread is illustrated with a graph generated from official data with some R code. The code, data, and link to the data source are shared along with the image on Commons, allowing others to update the graph.

For a site that aims to support education, it is frustrating that Commons does not support office file formats, including slide shows or spreadsheets, because it is hard to protect them from viruses. Slides and documents do get shared on Commons in the form of PDFs, but this discourages remixing and repurposing. Graphs can be shared as vector diagrams in the SVG (Scalable Vector Graphics) format which is editable in desktop publishing software but not in Microsoft Office. 
- Strength: Everything here has both an educational purpose and a licence allowing free reuse by anyone.

-Weakness: A confusing interface compared to commercial sites

\section{Top Tip:}

The icons above each image give instructions for reuse in various contexts (online, in print etc.). Below the image are links to download in different resolutions. For an image to use in a Powerpoint, downloading an 800-pixel-tall version will be more efficient than a 3000-pixel-tall version.

\section{Flickr}

To get a picture of an identifiable thing, not necessarily with an educational purpose, Flickr's truly enormous database of images is very likely to be helpful. Some cultural institutions such as the British Library or the Smithsonian share image collections here so, as with Commons, you can stumble on images of genuine historical interest.

From an uploader's perspective, Flickr has a very nice interface for adding and tagging files with description, location and other information. As with other services in this section (see Slideshare and Soundcloud below) there is a subscription version, but the free version gives you all the functions you practically need unless you are sharing a lot of content.

When I wanted images of the City of London and central Nairobi, and restricted the search to images I could use in a presentation without asking permission, Flickr obliged with these:
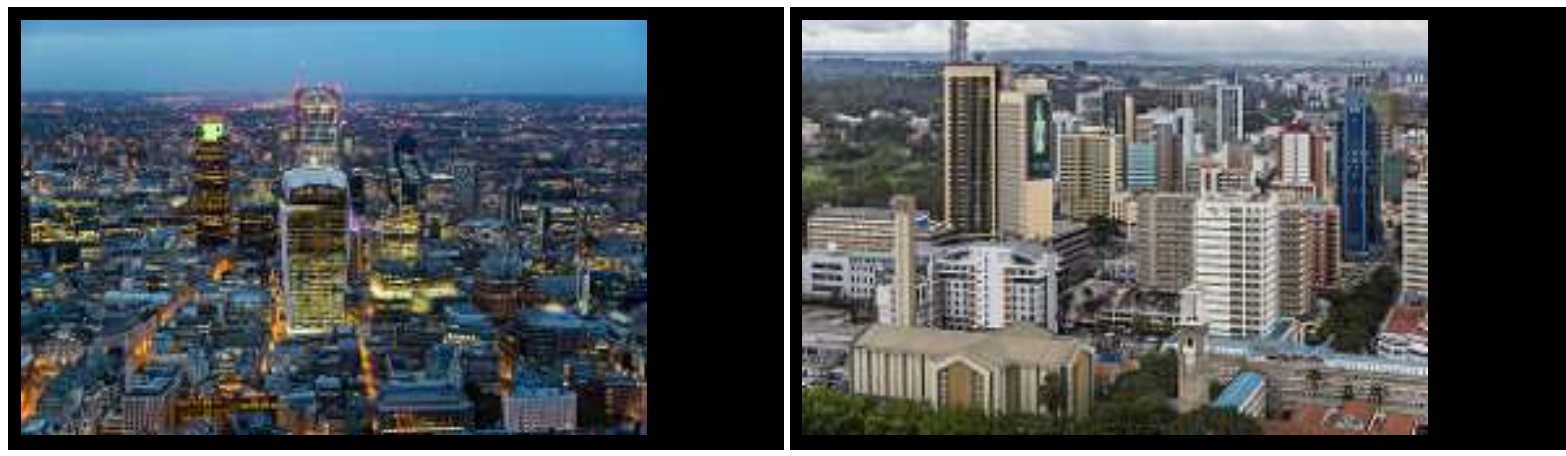

The Square Mile by Michael Garnett via Flickr, $\underline{\text { CC-BY-NC }}$

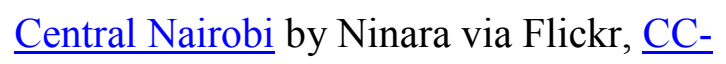
$\underline{\mathrm{BY}}$

- Strength: A huge number of images for every conceivable purpose

-Weakness: It can be difficult to find suitable content for academic use amongst all that. 


\section{Top Tips:}

-When you search on Flickr, the licence search options are in the top left of the screen, allowing you to only search for images that you can reproduce or modify. There are hundreds of millions of images on Flickr, so even a restricted search makes use of a large database.

- Beware that, intentionally or not, Flickr has a lot of incorrect licences. Someone might copy a page from The Economist and tag that image with a licence that allows free reuse, but the copyright in that image still resides with The Economist.

\section{iTunesU}

This is a service run by Apple that makes educational materials - including audio, video, and documents such as text transcripts - freely available through iTunes software. Whereas a site like YouTube lets anyone upload material, iTunesU has sharing agreements that cover a whole university, so you need to be in one of the partner institutions.

iTunesU content, like iTunes software itself, is free of charge to download, but not necessarily open in the sense of freely reusable: the licence is chosen by the institution.[2] Although iTunes works on a variety of platforms including iPads and desktop computers, there are users who cannot access it, so it is sensible to give an alternative route to the material. For example, the University of Oxford's audio programmes are released on the university's site as well as iTunes.

- Strength: convenience for end user, and a potentially very large audience for academic lectures.

-Weakness: a closed system that excludes a lot of users

60-Second Adventures in Economics is a series of short videos from the Open University, narrated by the comedian David Mitchell. It is available through iTunesU as both video and text transcripts, but also shared on YouTube. Imperial College Business School has audio programmes on a variety of economic topics, available both through iTunes and a direct download.

\section{Top Tip:}

You can make a web link to a resource in iTunesU, but the reader will have to have iTunes software on their computer to follow the link. Left-click on the download button and select "Copy link" from the menu that appears.

\section{SlideShare}

This site is mainly focused on presentation slides, but other document types are shared here as well. It gives a convenient way to turn a Powerpoint file into an interactive web page which can be shared and linked. SlideShare displays all the text from the 
presentation to make it accessible to search engines. There is also a download link for the presentation file, if the uploader has allowed it.

The web presentation treats the slideshow mostly as a succession of still images, so if your presentation uses complicated animation, it won't be visible in the online version. However, YouTube videos can be incorporated into the slides.

- Strength: focused on one type of resource and with an active contributor community

-Weakness: university-level material on economics and business is mixed in with much more from other educational levels, or presentations from businesses

Stephen Kinsella of the University of Limerick, Ireland, shares more than 150 presentations on SlideShare. The Office for National Statistics also has an official presence with short summaries of newly released statistics and presentations from its research events.

\section{Soundcloud}

This site is for sharing all kinds of audio, including lectures or academic discussions. As with YouTube, any user can subscribe to the channels they are interested in, and assemble tracks into customised playlists which can be bookmarked and shared. End users can listen via the web or via a free app on a mobile device.

A distinctive feature is that comments can attach to a particular point in the timeline, so you can see what they are reacting to.

- Strength: Great for subscribing and bookmarking audio from events and news sources.

-Weakness: Principally a music site with a relatively small proportion of academic content

The Economist, the International Monetary Fund, and the London School of Economics are among those with a SoundCloud presence. There are also archived recordings of past events including the Festival of Economics in Bristol and the Warwick Economics $\underline{\text { Summer School. }}$

\section{Footnotes}

[1] Mick Norman (2010) "The Economy of Free - Andrew Law, Director MultiPlatform Broadcasting, The Open University" University of Kent Unit for the Enhancement of Learning and Teaching

[2] Terese Bird (2011) "YouTube and iTunes U for Beyond-Text Open Educational Resources" Seminar presentation 


\section{Releasing your own resources}

The open approach can be summed up in three points:

1. Whenever you share materials, state your intentions

2. Be bold in adapting material and allowing your material to be adapted

3. Give credit where credit is due

\section{Contents}

- 4.1 State your intentions

- Performer's rights

- 4.2 Be bold and choose a liberal licence

- Avoiding exploitation

- 4.3 Give credit where credit is due

-Top tip:

\subsection{State your intentions}

Every reader is a potential remixer, so make your intentions clear when putting anything online, from a photograph to an online textbook. Unless the licence is specified by your work contract, you have some freedom of choice in how you license your work. Do you want the reader to be able to make their own copies, update it, combine it with other materials, or do you forbid use without your advance permission? If you want reserve all rights, say so.

Use a standard licence. Resist the temptation to put "for educational use only" or your own wording. These are not legally pinned-down. The Creative Commons licences have been worked on by legal experts in the UK and internationally, in consultation with educators and other users. Sharing ought to be straightforward for creators and users, and any ambiguity works against this.

There are seven variations of Creative Commons, with different combinations of clauses such as Attribution required (BY), Share-Alike (SA), and Non-Commercial (NC). With the default "all rights reserved", this gives eight total choices.[1] Arguably this is already too complicated: more options only make it more confusing.

When uploading media to Flickr, YouTube, or Wikimedia Commons, you choose a licence as part of the upload process. On other platforms, selecting a licence just takes a little more thought.

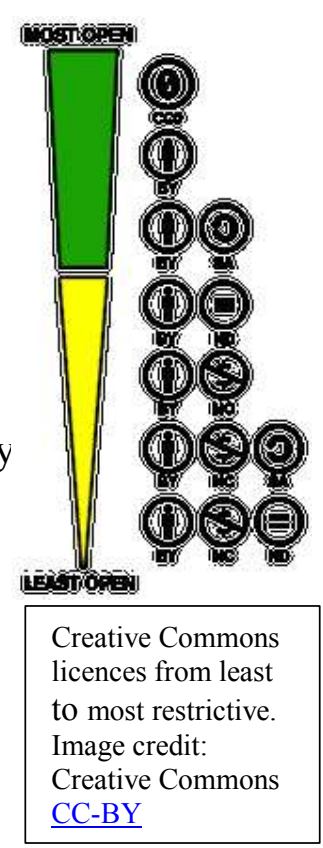


The official page for each Creative Commons licence explains how to attach that licence to your work. It can be as simple as including a single sentence, ideally with a web link. For extra clarity, and for resources that might be used offline, repeat the licence text.

Geographer Rich Harris of the University of Bristol has released his "Statistics for Geography and Environmental Science: an introduction in R" as a set of open resources. The first page of the Word document is a lay summary of the material's Attribution-NonCommercial ShareAlike licence, copied from the Creative Commons site.

A couple of considerations to be aware of:

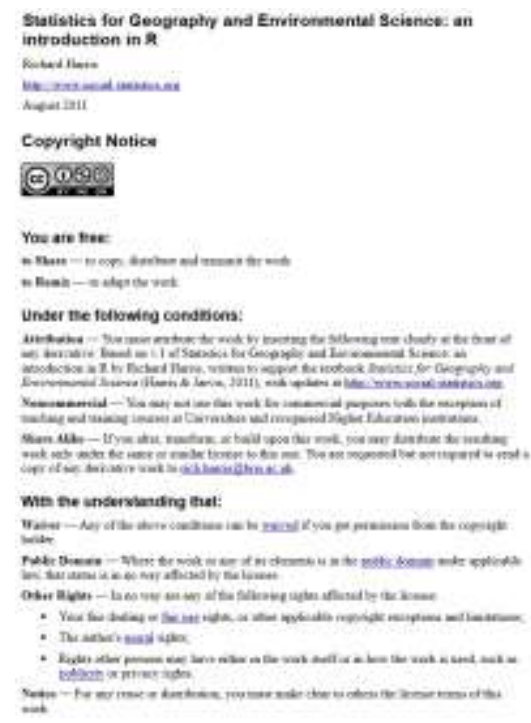

- Creative Commons licences do not necessarily cover software, so if you distribute code you may need to declare a separate licence for that. For example, for the DeSTRESS interactive graphs, the text has a Creative Commons AttributionShareAlike licence while the code has an MIT licence. With software as with anything else, there are many established licences, so it is clearer to adopt one of these rather than coming up with your own wording.

- If you share slides or documents based on an institutional template, these might include the logo of your institution or department. These logos are not themselves freely reusable, so it is normal to point that out in small print: see the TRUE project sidebar for an example.

\section{Performer's rights}

Performer's rights are a separate category of rights from copyright, and a lecture counts as a performance: there are rights associated with it, separate from the copyright in the presentation materials. The performer's rights exist whether or not the presentation is in private, and whether or not there is an audience.

Universities are increasingly wording employment contracts so that they automatically have permission from lecturers to share footage of performances done in work time. When this is not the case, you may have to declare in writing that you are happy for recordings of your performance to be public.

If you are sharing a video of someone else, such as a guest lecturer or conference speaker, you need their (ideally written) permission, including a mention of performer's rights as well as rights in their presentation materials.[2]

\subsection{Be bold and choose a liberal licence}

Before we had a global digital information network, spreading information to the widest possible audience was costly. Now, global access is the easiest option and restricting information to a limited audience is costly. So it is not access to information that needs to be justified, but barriers to the flow of information. 
It is almost impossible to anticipate the uses people will find for your work, and that this is a good thing. Putting a "No Derivatives" clause implies that the work is the best it could ever be for its purpose; that no tweaks anyone could make would improve it. In the case of educational material, it assumes that no one would have a need to update key facts. "No Derivatives" might be appropriate for something like a legal contract where even a small change of wording might render it useless, but not an educational resource which will need to be updated to remain useful.

\section{Avoiding exploitation}

How can we prevent exploitation of our work for commercial gain, while supporting those who use it for legitimate educational purposes? Creative Commons licences can have a "Non-commercial" clause which may seem an obvious solution. However, the clause has been notoriously hard to define in practice. When universities charge tuition fees and much research is published in subscription journals, education and research could be argued to be commercial activities. Educational use of material might involve posting it on YouTube or on a public blog, which would involve use of a commercial tool.

As Wild and Wilson (2013) write: "When choosing a CC BY-NC licence you might think that you only prevent use within the for-profit sector. This is not entirely true: you may actually prevent use within the public and non-profit sectors as well."'[3] Some of the most high-profile platforms for educational material actually forbid non-commercial clauses, for example Wikimedia Commons.

The Non-Commercial clause may not be the ideal way to prevent exploitation, but there are alternatives. One way is to release material in a public showcase: charging for something that people can get easily at no charge is a terrible business model. The ShareAlike clause, requiring any altered versions to have the same licence as the original, is a further layer of protection. It prevents anyone from making a derivative version of your work, and then placing that version under restrictive copyright.

The above examples assume that people obey copyright law, but outright plagiarism (ignoring copyright law) is a possibility. However, this is a risk that comes with putting material online in any form, whether openly licenced or not.

\subsection{Give credit where credit is due}

When you download and use Creative Commons-licensed materials you are implicitly accepting a legal contract, so take seriously the requirements of the licence. You are usually required to attribute the author in the manner they specify, so for example you might be required to link to their web site. Often you are required to specify the licence, and it is a good idea to do that anyway.

Again, since every reader is potentially a remixer, somebody who sees an image in your presentation might want to use the same image in their own works. This is another reason to give an explicit path to that source. So credit the author, the licence, and the site where you found the item, like the examples in Section 3, not just "found via Google" or "found on Wikipedia". 


\section{Top tip:}

If you use Creative Commons-licensed images in lecture slides, you can credit the source images in the foot of each slide or in a slide at the end.

\section{Footnotes}

[1] P2PU have a short online module to explain the different types of CC licence.

[2] "Recording lectures: legal considerations", a Jisc guide

"Recording lectures and participants' legal rights - what you should know" University of Manchester

[3] Joanna Wild \& Rowan Wilson (2013) "CC-By: what does it mean for scholarly articles?" Open Access Oxford 


\section{Conclusion}

The Budapest Declaration on Open Access promised that open access would "lay the foundation for uniting humanity in a common intellectual conversation and quest for knowledge". The Paris Declaration on Open Educational Resources said that open educational resources would "Improve both cost-efficiency and quality of teaching and learning outcomes". In one sense the promised revolution has not materialised: the impact so far within formal education may seem small. However, openness has transformed the online world that we all inhabit, whether as students, staff, or members of the public.[1] Some of the most popular sites on the internet are open educational resources, and together they share hundreds of millions of images, articles and other files for educational use.

Students come to university already familiar with Khan Academy, with Wikipedia, with iTunes and other openly available sources. Their choice of degree may well have been shaped by video clips and other materials found online. Openly available materials do not replace the university experience, but they can complement it, as supplements to diversify the presentation of an idea, or as building blocks to be repurposed in making new materials. They are a commons that anyone can draw on, and which professional educators are best placed to make innovative use of.

\section{Footnotes}

[1] Weller, M. 2014. Battle for Open: How openness won and why it doesn't feel like victory. London: Ubiquity Press. DOI: $\underline{10.5334 / \mathrm{bam}}$ 


\section{Further reading}

Association for Learning Technology Open Education Resources Special Interest Group (ALT OER SIG). This is a community, mainly based in UK higher education but with international contributions. It is one of the focal points for discussion of open practice in education - not just open educational resources - and you can follow or join in the discussion via its open mailing list, webinars, and community blog.

Open Education Handbook (2014), created as a project of the Education Working Group of the Open Knowledge Foundation, this aims to cover the area of open education quite comprehensively, with 47 sections each with links and pointers. This edition is hosted by Wikibooks, so if you see something you want to update, go ahead and click "Edit".

Jisc guide to Open Educational Resources (revised version 2014) a guide for "senior managers, learning technologists, technical staff and educators interested in releasing OERs to the education community." and as such has an emphasis on institutional strategy.

Open Education: Fundamentals and Approaches (2017) a set of course materials for teaching staff, with five modules addressing different aspects of open education, created by a European project with partners including Coventry University. 